\title{
The Primary Low Grade Ovarian Endometrioid Stromal Sarcoma - A rare entity in Gynecologic Surgical Pathology -
} A case report

\author{
Alessandro D'Amuri MD*, Marcello Filotico MD \\ Department of Pathologic Anatomy, Hospital "Card. G. Panico", 73039 Tricase LE, Italy
}

${ }^{*}$ Correspondence author: Alessandro D’Amuri MD, Department of Pathologic Anatomy, Hospital “Card. G. Panico”, 73039 Tricase LE, Italy; E-mail: damuri.alessandro@ gmail.com

Received: August 08, 2018; Accepted: August 23, 2018; Published: September 05, 2018;

\section{Summary}

Rare case of primitive stromal endometrioid sarcoma of the ovary in a 57-year-old woman was presented. Lesion of $17 \mathrm{~cm} \mathrm{x} 16 \mathrm{~cm} \times 9$ $\mathrm{cm}$ size located in the right ovary. At the uterine level are some foci of adenomyosis. Epidemiology and histogenesis of these neoplasms and their immunophenotypic profile are discussed.

Case Report: A woman of the 50s has been suffering from abdominal pain and intestinal transit disorders for several months. An abdominal ultrasound shows the presence of a mass at the right half of the abdomen. At the intervention, there is a mass in correspondence of the right ovary. The patient undergoes bilateral hystero-salpingooophorectomy.

Macroscopic: The surgical sample of the right ovary consists of a mass of $17 \times 16 \times 9$ centimeters. The sectioned surface presents cystic areas with citrine liquid content alternating with areas of solid tan yellow appearance. The left ovary and the uterus do not show significant macroscopic alterations

Material and Methods: Several fragments are taken in various areas of the right ovarian tumor mass. Fragments are taken from the left ovary, fallopian tubes, cervix, and the body of the uterus. The material was fixed in formalin and in paraffin embedded. The sections were colored with $\mathrm{H} \& \mathrm{E}$ and subjected to a panel of antibodies for immunohistochemistry. (Table 1)

Microscopic: The normal structure of the ovary was no longer recognizable. Wide bands of fibrous tissue reminiscent of ovarian fibroma, delimit irregular areas in shape and size. In the context of these areas, it is present. a massive proliferation of roundish, small mononuclear cells (Figure 1a).The elements are aggregated in a diffuse manner, usually compact, sometimes with aspects of a honeycomb (Figure 1b). The proliferation winds between the fibrous bands with tongue-like extensions (Figure $\mathbf{1} \mathbf{c}, \mathbf{d}$ ).

There is also an abundant vascular component of the arteriolar type reminiscent of the spiral arterioles of the endometrial stroma (Figure $2 \mathbf{a}, \mathbf{b}, \mathbf{c}, \mathbf{d})$. The results of the immunohistochemical investigations are shown in (Table 2)
Table 1

\begin{tabular}{|l|l|}
\hline CKAE1-AE3 & Monoclonal 1:50 DAKO \\
\hline VIM & Monoclonal 1: 50 DAKO \\
\hline EMA & Monoclonal 1: 50 DAKO \\
\hline CD10 & Monoclonal 1: 50 DAKO \\
\hline PGR & Monoclonal 1: 50 DAKO \\
\hline ER & Monoclonal 1: 40 DAKO \\
\hline SMA & Monoclonal 1: 50 DAKO \\
\hline DESM & Monoclonal 1:50 DAKO \\
\hline INIB & Monoclonal 1:50 DAKO \\
\hline WT1 & Monoclonal 1: 50 DAKO \\
\hline Cyclin D1 & Monoclonal 1:50 DAKO \\
\hline PAX8 & Monoclonal 1: 50 Biocare \\
\hline CD117 & Polyclonal 1: 400 DAKO \\
\hline P53 & Monoclonal 1: 50 DAKO \\
\hline Ki67 & Monoclonal 1: 75 DAKO \\
\hline
\end{tabular}

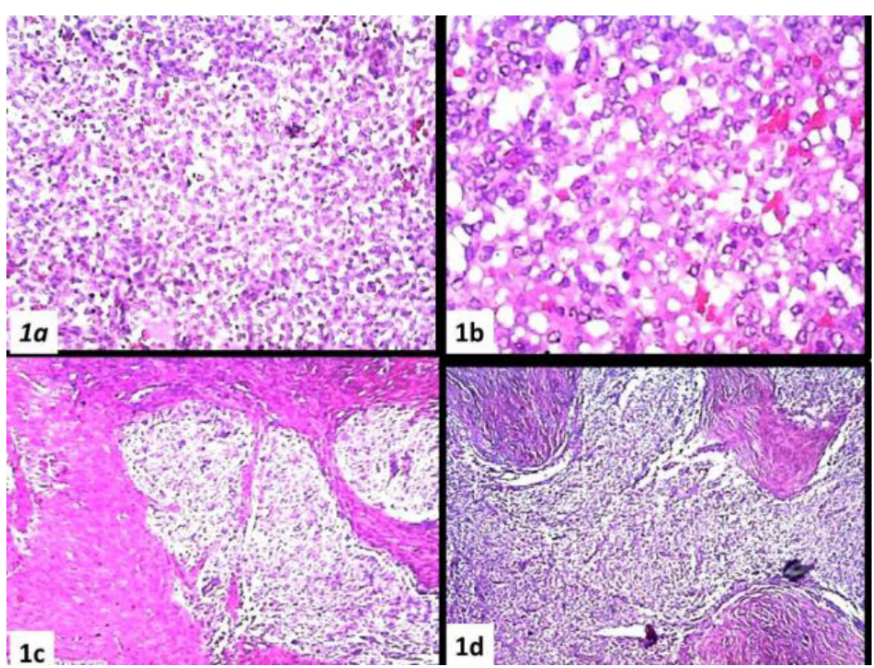

Figure 1. (a) Massive proliferation of roundish, small mononuclear cells, (b) Sometimes with aspects of a honeycomb, (c, d) The proliferation winds between the fibrous bands with tongue-like extensions 
Alessandro D'Amuri and Marcello Filotico (2018) The Primary Low Grade Ovarian Endometrioid Stromal Sarcoma - A rare entity in Gynecologic Surgical Pathology - A case report.

Table 2

\begin{tabular}{|c|c|c|c|c|c|c|c|c|c|c|c|c|c|c|}
\hline KAE1-AE3 & VIM & EMA & CD10 & PGR & ER & SMA & DESM & INIB & WT1 & CYCLD1 & PAX8 & CD117 & P53 & KI67 \\
\hline $\begin{array}{c}+- \\
\text { Fig.5b }\end{array}$ & $\begin{array}{c}+ \\
\text { Fig.5a }\end{array}$ & - & $\begin{array}{c}+ \\
\text { Fg.3a }\end{array}$ & $\stackrel{+}{+}$ & $\begin{array}{c}+ \\
\text { Fig.3c }\end{array}$ & $\stackrel{+-}{\text { Fig. } 3 d, 4 a, b}$ & - & $\begin{array}{c}-+^{a} \\
\text { Fig.5c }\end{array}$ & $\begin{array}{c}+- \\
\text { Fig.4c,d }\end{array}$ & - & - & - & - & $\begin{array}{l}>10 \% \\
\text { Fig.5d }\end{array}$ \\
\hline
\end{tabular}

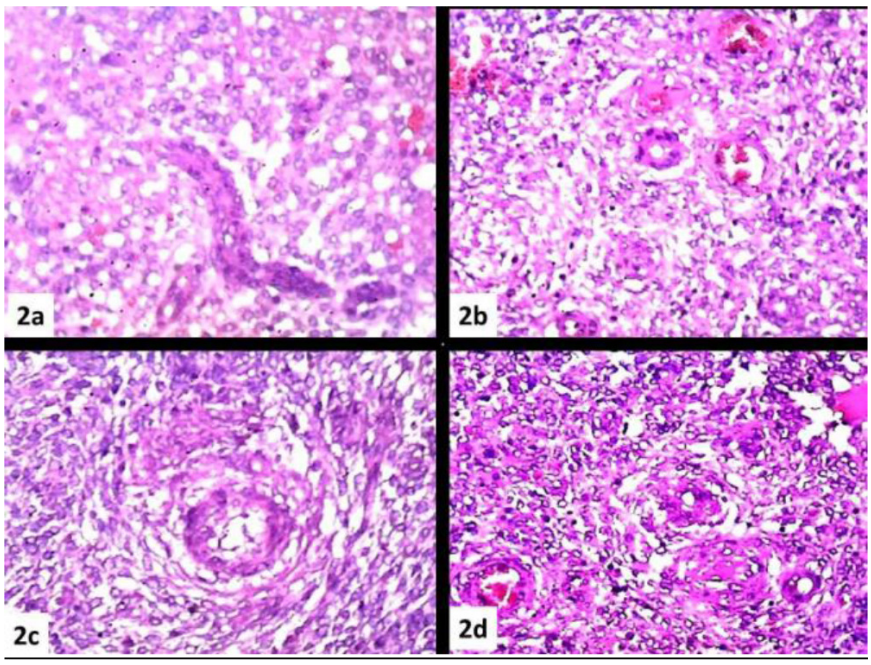

Figure 2. (a), (b), (c), (d) Abundant vascular component of the arteriolar type reminiscent of the spiral arterioles of the endometrial stroma

The morphological pattern and immunohistochemical profile favor the diagnosis endometrioid stromal sarcoma low grade of the ovary. The absence of a similar lesion at the uterine level or elsewhere allows the term primary to be added to the diagnosis.

\section{Discussion}

Ovarian neoplasms presenting the morphological characters of the endometrial stroma has been reported since the 1960s [1], and later in the early 80s [2]. Only in 1984, in a series of 23 cases studied by Scully et al. did the term Endometrioid Stromal Sarcoma of the ovary (ESS) appeared in the literature. Under this term in the article, are included both lesions with exclusively ovarian localization, but also those associated with a similar synchronous or metachronous uterine lesion [3]. In this publication, the morphological characters of the lesions are defined as completely superimposable to those of the uterine counterpart. The largest primitive ESS series of the ovary report the study of 27 cases and to our knowledge, represents, to date, the most detailed study on the subject [4].
The WHO 2003 classification of Ovarian Tumors poses these neoplasms between the Surface Epithelial- Stromal tumors and precisely among Endometrioid tumors giving them the following definition: "Endometrioid stromal sarcoma (ESS) is a monophasic sarcomatous tumour characterized by a diffuse proliferation of neoplastic cells similar to stromal cells of the proliferative endometrium. At its periphery, the tumour exhibits a typical infiltrative growth pattern."[5]. The WHO 2014 classification includes these neoplasms between Mesenchymal Tumors, giving the following definition: "A Mesenchymal Tumour identical to low-grade uterine endometrial stromal sarcoma" [6].

In terms of nosographic precision, the definition of 2003 seems to us more appropriate as the endometrial stroma is a Mullerian derivative which, in turn, originates from the celomatic mesoderm and not from the mesenchyme which, as is known, is that part of the mesoderm from which originate the connective tissues, bone, cartilage, blood vessels, and lymphatics and not the organs of the urogenital system. In a series of 20 primary extrauterine ESS we can see how the case series is distributed on all the organs of the celomatic area: ovaries, salpinges, pelvic cavity and abdominal wall [7].The same area of distribution of endometriosis. An association with endometriosis has been reported in about $50 \%$ of cases. But for this, a mandatory interrelationship between the two phenomena cannot be inferred $[1,2,7],[8-11]$.

The extensive and detailed description of the morphologic pattern of these lesions reported in the aforementioned publication [4] can be summarized as follows: The most frequent pattern is that of a widespread proliferation of small roundish elements with scant cytoplasm, closely packed. The proliferation is often intersected by a band of fibrous tissue reminiscent of the ovarian fibroma; Sex cord differentiation is present in about $25 \%$ of cases. Smooth muscle differentiation is present in about $20 \%$ of cases. The characteristic tongue-like infiltration and intravascular penetration are rarely seen in ovarian localization. Small vessels with the spiral arterioles characters of the proliferative phase, with an often dilated lumen and curvilinear trend (low-grade fibromixosarcoma-like), are disseminated in the proliferation.

The recommended Immunohistochemical panel is comparable to that adopted for similar uterine neoplasms :

\begin{tabular}{|c|c|c|c|c|c|c|c|c|c|c|c|}
\hline CD10 & SMA & DESM & hCALDESM & PGR & ER & VIM & Wt1 & AR & CALP & $\beta$ CAT & KAE1-AE3 \\
\hline+ & + & - & - or + & + & + & & + & + or- & + or- & + or- & - or + \\
\hline
\end{tabular}


[12] From the biomolecular point of view, there are two subsets of ESS, JAZF1-SUZ12 or equivalent genetic rearrangements and another characterized by YWHAE-FAM22 genetic fusion histologically of higher grade and clinically more aggressive. This second subset expresses consistently Cyclin D1, with coexistent negativity for CD10 and PGR [13]. A wide range of primitive and secondary ovarian lesions (fibroma, thecoma, fibrosarcoma, mesodermal adenosarcoma, metastatic Gist) should be placed in differential diagnosis of these lesions, which in addition to being particularly rare, may contain aspects related to other entities (sex cord, thecoma) of the neoplastic ovary pathology.

A recent survey of 14 patients yielded the following results. The average age of patients is around 49 years with a median of 51 . Nine (64\%) was classifiable as low-grade and $5(36 \%)$ as high- grade. After a 65 months F.U., all low-grade Pts were alive. 33\% of them had developed a relapse. Of high-grade Pts was alive without recurrence only $1 \mathrm{Pt}$, the other 4 develops relapses and two died due to the progress of the disease [14]. The case observed by us can rightly be numbered in the rare case of this neoplasm that according to a recent review of the literature amounts to, to date, less than 100 [14].

In fact, the morphological parameters are respected both as regards the cellular morphology and its organization (Figuresla-b), the tongue-like character of the infiltration (Figures 1c-d), the vascular component with the characteristic appearance of the spiral arterioles (Figures $2 \mathrm{a}-\mathrm{b}-\mathrm{c}-\mathrm{d}$ ), and the fibrous component with the aspects of the ovarian fibroma (Figure.1c). Immunohistochemistry showed diffuse and intense positivity for Vimentin (Figure 5a), CD10 (Figure 3a),, PGR (Figure 3b), ER (Figure 3c), Focal and sporadic for $\mathrm{CK}(5 \mathrm{~b})$, positive SMA on the level of the muscular tunics of the vessels, even just sketched out (Figures 3d,4a-b), WT1 is weakly positive in scattered elements while exhibiting strong positivity in the muscular tunics of the spiral arterioles (Figures (4c.d). Scattered elements from fibroblastic morphology exhibit positivity for INIBIN in the context of the fibrous bands (Figure.5c) The Ki67 proliferation index stands at values below 10\% (Fig.5d). The morphologic pattern and the immunohistochemical profile suggest considering this case as a low grade.

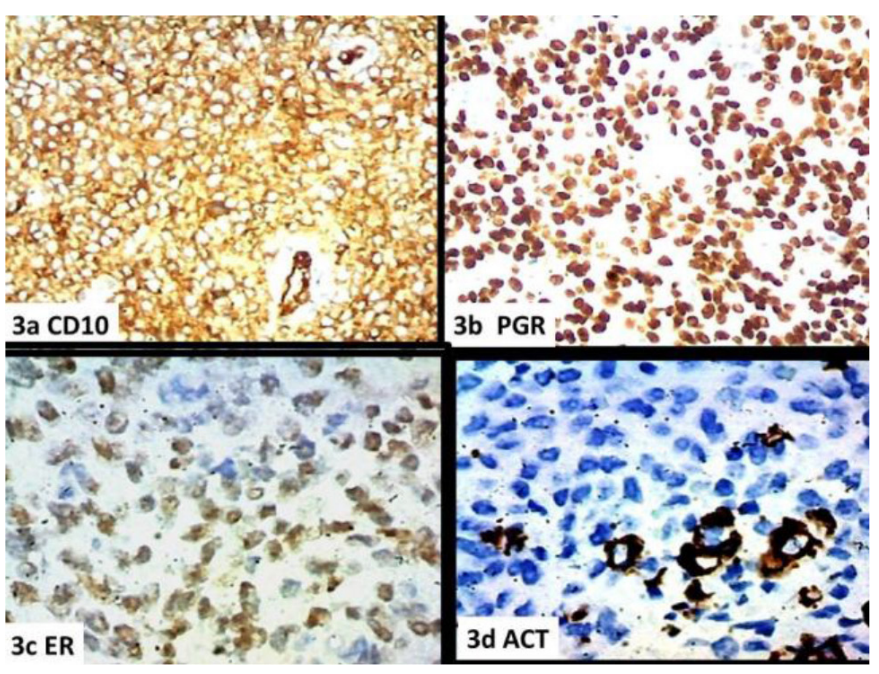

Figure 3. a) CD10, b) PGR, c) ER, d) SMACT

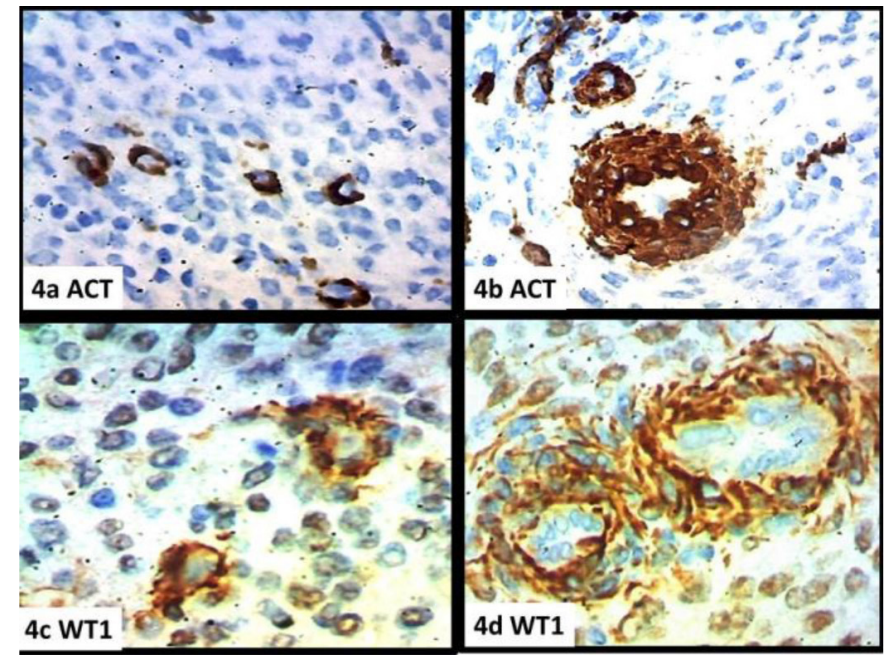

Figure 4. a) SMACT, b) SMACT (arteriole), (c, d) WT1 (arteriole)

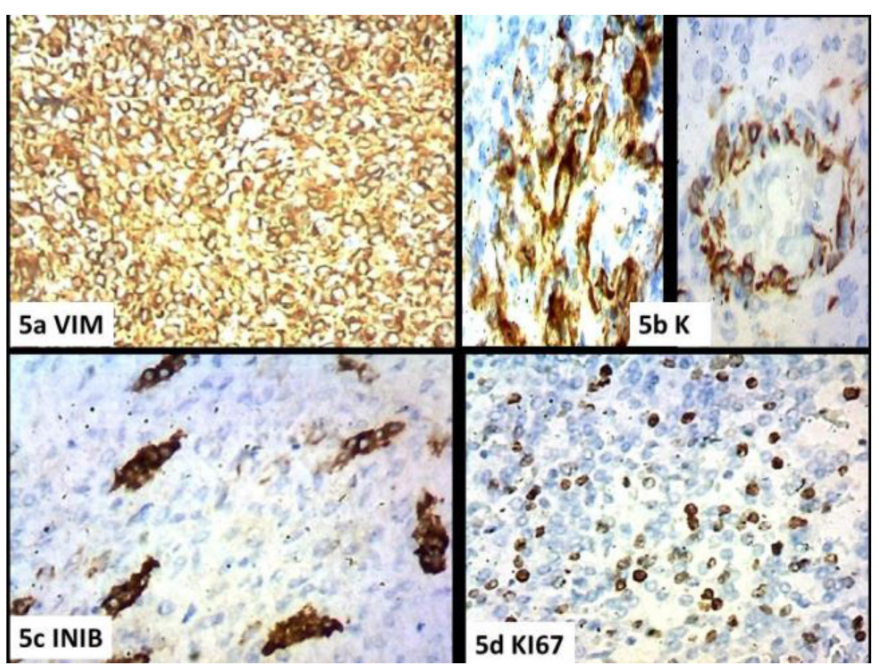

Figure 5. a) Vim, b) Keratin AE1-AE3, c) INIBIN, d) KI67

\section{References}

1. Koller, Rygh (1960) A case of stromal endometriosis originating from ovarian endometriosis. Aciu Obstei Gynecol Scund 39: 178-183.

2. Silverberg SG, Fernandez FN (1981) Endolymphatic stromal myosis of the ovary: a report of three cases and literature review. Gynecol Oncol 12: 129-138. [crossref]

Young RH, Prat J, Scully RE (1984) Endometrioid Stromal Sarcomas of the Ovary A Clinicopathologic Analysis of 23 Cases. Cancer 53: 1143-1155. [crossref]

4. Oliva E, Egger JR, Young RH (2014) Primary Endometrioid Stromal Sarcoma of the Ovary A Clinicopathologic Study of 27 Cases With Morphologic and Behavioral Features Similar to Those of UterineLow-grade Endometrial Stromal Sarcoma. Am J Surg Pathol 38: 305-315. [crossref]

5. WHO (2003) Classification of Tumours - Pathology \& Genetics-Tumours ofbthebreast and Femalegenital Organs- IARC Press, Lyon

6. WHO (2014) Classification of Tumours - Pathology \& Genetics Tumours of the breast and Female genital Organs- IARC Press, Lyon

7. Chang KL, Crabtree GS, Lim-Tan SK, Kempson RL, Hendrickson MR (1993) Primary extrauterine endometrial stromal neoplasms: a clinicopathologic study of 20 cases and a review of the literature. Int J Gynecol Pathol 12: 282-296. [crossref]

8. Baiocchi G, Kavanagh JJ, Wharton JT (1990) Endometrioid stromal sarcomas arising from ovarian and extraovarian endometriosis: report of two cases and review of the literature. Gynecol Oncol 36: 147-151. [crossref]

9. Lan C, Huang X, Lin S, Cai M, Liu J (2012) Endometrial Stromal Sarcoma Arising from Endometriosis: A Clinicopathological Study and Literature Review. Gynecol Obstet Invest 74: 288-297. [crossref]

10. Usta TA, Sonmez SE, Oztarhan A, Karacan T (2014) Endometrial stromal sarcoma in the abdominal wall arising from scar endometriosis. J Obstet Gynaecol 34: 541542. [crossref] 
Alessandro D'Amuri and Marcello Filotico (2018) The Primary Low Grade Ovarian Endometrioid Stromal Sarcoma - A rare entity in Gynecologic Surgical Pathology - A case report.

11. Ju A Back, Myeong Gyune Choi, U Chul Ju, Woo Dae Kang, Seok Mo Kim (2016) A case of advanced stage endometrial stromal sarcoma of the ovary arising from endometriosis. Obstet Gynecol Sci 59: 323-327.

12. Prichard J, Kaspar H.G (2015) Handbook of Practical Immunohistochemistry: Frequently Asked Questions (positions in Kindle 20288-20289). Kindle Ed, Springer New York.
13. Lee CH, Ali RH, Rouzbahman M, Marino-Enriquez A, Zhu M, et al. (2012) Cyclin D1 as a diagnostic immunomarker for endometrial stromal sarcoma with YWHAEFAM22 rearrangement. Am J Surg Pathol 36: 1562-1570. [crossref]

14. Xie W, Bi X, Cao D, Yang J, Shen K, et al. (2017) Primary endometrioid stromal sarcomas of the ovary: a clinicopathological study of 14 cases with a review of the literature. Oncotarget 8: 63345-63352. [crossref]

\section{Citation:}

Alessandro D'Amuri and Marcello Filotico (2018) The Primary Low Grade Ovarian Endometrioid Stromal Sarcoma - A rare entity in Gynecologic Surgical Pathology - A case report. Integr Gyn Obstet J Volume 1(2): 1-4. DOI: 10.31038/IGOJ.2018110 